\title{
Indirect comparison of 48-week efficacy and safety of long-acting cabotegravir and rilpivirine maintenance every 8 weeks with daily oral standard of care antiretroviral therapy in participants with virologically suppressed HIV-1-infection
}

Vasiliki Chounta ( $\square$ vasiliki.x.chounta@viivhealthcare.com )

ViiV Healthcare

Sonya J Snedecor

Pharmerit - an OPEN Health Company

Sterling Wu

GlaxoSmithKline

Nicolas Van de Velde

ViiV Healthcare

Research article

Keywords: (3-10 keywords maximum) anti-HIV agents/administration and dosage, anti-retroviral agents/therapeutic use, HIV infections/drug therapy, indirect treatment comparison, long-acting

Posted Date: September 14th, 2020

DOI: https://doi.org/10.21203/rs.3.rs-72129/v1

License: (c) (1) This work is licensed under a Creative Commons Attribution 4.0 International License. Read Full License 


\section{Abstract}

\section{Background}

Efficacy and safety of long-acting cabotegravir (CAB) + rilpivirine (RPV) every 8 weeks (Q8W) versus daily oral standard of care (SoC) maintenance in treatment-experienced individuals with virologically suppressed human immunodeficiency virus type 1 (HIV-1) has not been directly compared in randomized clinical trials. This analysis aimed to indirectly compare these regimens.

\section{Methods}

An adjusted indirect treatment comparison of CAB + RPV Q8W with daily oral SoC was performed, using Phase 3 data from studies of CAB + RPV every 4 weeks vs SoC (Q4W; ATLAS/FLAIR, $n=591$ per group) and a Phase $3 \mathrm{~b}$ trial of CAB + RPV Q8W vs Q4W (ATLAS-2M [excluding participants with prior CAB + RPV exposure]; $n=327$ per group). Eligible participants were virologically suppressed (viral load $<50 \mathrm{HIV}-1$ ribonucleic acid (RNA) copies/mL), treatment-experienced individuals with HIV-1-infection. Treatment efficacy and safety at Week 48 included virologic suppression and lack of virologic suppression (proportion of participants with plasma HIV-1 RNA $<50$ copies/mL or $\geq 50$ copies $/ \mathrm{mL}$, respectively; both as per FDA snapshot algorithm), CD4-cell count change from baseline, no virologic data, discontinuations due to adverse events (AEs), and overall AEs, serious AEs and Grade 3-5 AEs excluding injection-site reactions. Baseline characteristics between the Q4W arms of ATLAS/FLAIR and ATLAS-2M showed no significant differences or differences were not judged to be clinically relevant, apart from participants switching from a baseline third active drug class; more participants switched from integrase strand inhibitors in ATLAS/FLAIR, and from non-nucleoside reverse transcriptase inhibitors in ATLAS-2M. A subgroup analysis stratified by baseline third active drug class was performed.

Results

Injections of CAB + RPV Q8W showed no significant differences across efficacy and safety outcomes versus daily oral SoC. The subgroup analysis found there were no significant differences on virologic suppression or lack of virologic suppression for any baseline third active drug class subgroups. These results suggest that $\mathrm{CAB}+\mathrm{RPV} \mathrm{Q} 8 \mathrm{~W}$ is non-inferior to daily oral SoC.

\section{Conclusions}

This analysis supports the therapeutic potential of CAB + RPV Q8W for virologically suppressed people living with HIV-1 infection seeking an alternative maintenance treatment option to daily oral SoC.

Trial registration

NCT02938520, NCT02951052, NCT03299049

\section{Background}


The efficacy of human immunodeficiency virus type 1 (HIV-1) treatments has improved steadily over the past few decades, with combination antiretroviral therapy (CART) now being the standard of care (SoC) (1-3). Typically, cART is comprised of two nucleoside/nucleotide reverse transcriptase inhibitors (NRTIs) plus a third active drug from a different class (1-3). New cART regimens of two (i.e. dolutegravir [DTG] + lamivudine) rather than three drugs have recently been included in guidelines $(1,3)$.

The primary goal of cART is to reduce HIV-1-associated morbidity and mortality by maximally inhibiting HIV-1 replication, as measured by viral load (1). An emerging clinical treatment strategy is to switch successfully treated individuals with virologically suppressed HIV-1-infection to maintenance regimens containing fewer drugs, potentially simplifying administration and reducing long-term drug toxicities, among other reasons (4-8). Currently, all available cART options are administered daily as oral formulations (1). Although highly efficacious and well tolerated, daily oral ART can affect the well-being of some people living with HIV (PLHIV) due to it being a daily reminder of HIV status and its potential to allow unwanted disclosure of HIV infection (7, 9-12). In addition, for some PLHIV, maintaining optimal adherence levels can be challenging due to lifestyle factors, forgetfulness, or other reasons (13).

Cabotegravir (CAB), an integrase strand transfer inhibitor (INSTI), has been developed as a long-acting injectable drug used in combination with long-acting injectable rilpivirine (RPV), a non-nucleoside reverse transcriptase inhibitor (NNRTI), for virologically suppressed PLHIV. This combination therapy may improve drug adherence, while reducing the burden and potential emotional impact of daily treatment. The non-inferiority of CAB + RPV LA administered every 4 weeks (Q4W) in maintaining virologic suppression compared with daily oral SoC ART has been demonstrated in two pivotal Phase 3 studies (Antiretroviral Therapy as Long-Acting Suppression [ATLAS] and First Long-Acting Injectable Regimen [FLAIR]) as well as in a pooled analysis of these studies (14-16). Participants receiving CAB + RPV LA reported greater satisfaction with and preference for this regimen over previous oral therapy (14-16). Additionally, the ATLAS every 2 months (ATLAS-2M) Phase 3b study demonstrated the non-inferiority of CAB + RPV LA (600 mg + $900 \mathrm{mg}$ ) administered every 8 weeks (Q8W) versus CAB + RPV (400 mg + $600 \mathrm{mg}$ ) Q4W over a 48-week treatment period, showing that virologic suppression can be maintained with a different dose and a reduced frequency of dosing. In ATLAS-2M, study participants preferred the Q8W dosing over daily oral or Q4W dosing (17).

No randomized clinical trial comparing CAB + RPV LA Q8W and daily oral SoC regimens is currently available to allow a direct comparison of efficacy and safety of these maintenance regimens in treatment-experienced individuals with virologically suppressed HIV-1 infection. Therefore, the current analysis aimed to indirectly compare CAB + RPV LA Q8W with daily oral SoC maintenance regimens 48 weeks after treatment switch from SoC.

\section{Methods}

\section{Study design}


An adjusted indirect comparison of CAB + RPV LA Q8W with daily oral SoC was conducted according to the International Society for Pharmacoeconomics and Outcomes Research (ISPOR) guidelines on good research practices for indirect treatment comparisons (18). To date, the only trial of CAB + RPV LA Q8W is ATLAS-2M which compared this regimen with CAB + RPV LA Q4W; the available trials that compare CAB + RPV LA with daily oral SoC maintenance treatments have used a Q4W CAB + RPV LA regimen (ATLAS and FLAIR). Thus, the evidence base for this analysis of CAB + RPV LA Q8W versus daily oral SoC was necessarily limited to the ATLAS, FLAIR, and ATLAS-2M trials $(14,15,17)$. An anchored Bucher's frequentist adjusted indirect treatment comparison was used for this analysis of CAB + RPV LA Q8W and oral daily SoC, with CAB + RPV LA Q4W as the common comparator (19). Since combining studies should only be considered if they are clinically and methodologically similar, we employed the PICOS approach to compare trials in terms of population (P), intervention (I), comparator (C), outcome (O), and study design (S) (Table 1). The ATLAS, FLAIR, and ATLAS-2M trials were all 1:1 randomized, open-label studies, evaluating non-inferiority in efficacy after switching to the intervention of interest in a virologically suppressed population at Week 48 with primary and secondary endpoints being identical between the trials included in the analysis (Table 1). 
Table 1

Summary of study characteristics of the ATLAS, FLAIR, and ATLAS-2M trials

\begin{tabular}{|c|c|c|c|c|c|}
\hline $\begin{array}{l}\text { Trial } \\
\text { acronym } \\
\text { (Author } \\
\text { year) }\end{array}$ & Study design & Countries/region & $\begin{array}{l}\text { Participant } \\
\text { eligibility criteria }\end{array}$ & $\begin{array}{l}\text { Intervention/ } \\
\text { comparator }\end{array}$ & Endpoints \\
\hline $\begin{array}{l}\text { ATLAS } \\
\text { (Swindells } \\
2020) \\
(15)\end{array}$ & $\begin{array}{l}\text { Randomized, } \\
\text { multicenter, } \\
\text { parallel- } \\
\text { group, } \\
\text { open-label, } \\
\text { Phase } 3\end{array}$ & $\begin{array}{l}\text { Argentina } \\
\text { Australia } \\
\text { Canada } \\
\text { Europe } \\
\text { Mexico } \\
\text { Republic of } \\
\text { Korea } \\
\text { Russian } \\
\text { Federation } \\
\text { South Africa } \\
\text { USA }\end{array}$ & $\begin{array}{l}\text { - On initial or } \\
\text { second ARV } \\
\text { regimen } \geq 6 \\
\text { months prior } \\
\text { to screening } \\
\text { - Prior switch only } \\
\text { for } \\
\text { tolerability/safety, } \\
\text { access to } \\
\text { medications, or } \\
\text { convenience/ } \\
\text { simplification, and } \\
\text { NOT due to } \\
\text { treatment failure } \\
\text { - HIV- } 1 \text { RNA }<50 \\
\text { copies/mL at } \\
\text { screening and } \geq 2 \\
\text { HIV- } 1 \text { RNA } \\
\text { measurements }< \\
50 \text { copies/mL in } \\
\text { the } 12 \text { months } \\
\text { prior to screening }\end{array}$ & $\begin{array}{l}\text { - CAB + RPV } \\
\text { Q4W } \\
\text { • Continued } \\
\text { cART SoC } \\
\text { therapy }\end{array}$ & $\begin{array}{l}\text { - Primary: \% } \\
\text { participants } \\
\text { with HIV-1 } \\
\text { RNA } \geq 50 \\
\text { copies/mL } \\
\text { at Week } 48 \\
\text { - Key } \\
\text { secondary: } \\
\text { participants } \\
\text { with HIV-1 } \\
\text { RNA }<50 \\
\text { copies/mL } \\
\text { at Week } 48\end{array}$ \\
\hline $\begin{array}{l}\text { FLAIR } \\
\text { (Orkin } \\
2020) \\
(14)\end{array}$ & $\begin{array}{l}\text { Randomized, } \\
\text { multicenter, } \\
\text { open-label, } \\
\text { noninferiority, } \\
\text { Phase } 3\end{array}$ & $\begin{array}{l}\text { Canada } \\
\text { Europe } \\
\text { Japan } \\
\text { Russian } \\
\text { Federation } \\
\text { South Africa } \\
\text { USA }\end{array}$ & $\begin{array}{l}\text { - Treatment naïve } \\
\text { at screening } \\
\text { - } 20 \text { weeks } \\
\text { induction period } \\
\text { with } \\
\text { DTG/ABC/3TC } \\
\text { - HIV-1 RNA < } 50 \\
\text { copies/mL prior to } \\
\text { randomization }\end{array}$ & $\begin{array}{l}\cdot \mathrm{CAB}+\mathrm{RPV} \\
\mathrm{Q} 4 \mathrm{~W} \\
\cdot \mathrm{DTG}+\mathrm{ABC} \\
+3 \mathrm{TC}\end{array}$ & $\begin{array}{l}\text { - Primary: \% } \\
\text { participants } \\
\text { with HIV-1 } \\
\text { RNA } \geq 50 \\
\text { copies/mL } \\
\text { at Week 48 } \\
\text { - Key } \\
\text { secondary: } \\
\text { participants } \\
\text { with HIV-1 } \\
\text { RNA<50 } \\
\text { copies/mL } \\
\text { at Week 48 }\end{array}$ \\
\hline
\end{tabular}

aParticipants with prior CAB + RPV LA exposure were excluded from the current analysis

3TC, lamivudine; ABC, abacavir; ATLAS, Antiretroviral Therapy as Long-Acting Suppression; ATLAS2M, ATLAS every 2 months; CAB, cabotegravir; cART, combination antiretroviral therapy; DTG, dolutegravir; FLAIR, First Long-Acting Injectable Regimen; LA, long-acting; HIV-1, human immunodeficiency virus type 1; PI, protease inhibitor; Q4W, every 4 weeks; Q8W, every 8 weeks; RNA, ribonucleic acid; RPV, rilpivirine; SoC, standard of care 


\begin{tabular}{|c|c|c|c|c|c|}
\hline $\begin{array}{l}\text { Trial } \\
\text { acronym } \\
\text { (Author } \\
\text { year) }\end{array}$ & Study design & Countries/region & $\begin{array}{l}\text { Participant } \\
\text { eligibility criteria }\end{array}$ & $\begin{array}{l}\text { Intervention/ } \\
\text { comparator }\end{array}$ & Endpoints \\
\hline $\begin{array}{l}\text { ATLAS- } \\
\text { 2M } \\
\\
\text { (Overton } \\
2020)(17, \\
35)\end{array}$ & $\begin{array}{l}\text { Randomized, } \\
\text { multicenter, } \\
\text { parallel- } \\
\text { group, } \\
\text { open-label, } \\
\text { noninferiority, } \\
\text { Phase } 3\end{array}$ & $\begin{array}{l}\text { Argentina } \\
\text { Australia } \\
\text { Canada } \\
\text { Europe } \\
\text { Mexico } \\
\text { North America } \\
\text { Republic of } \\
\text { Korea } \\
\text { Russian } \\
\text { Federation } \\
\text { South Africa } \\
\text { USA }\end{array}$ & $\begin{array}{l}\cdot 2 \text { documented } \\
\text { HIV-1 RNA viral } \\
\text { load } \\
\text { measurements } \\
<50 \text { copies/mL in } \\
\text { each past } 2,6- \\
\text { month periods and } \\
\text { at study entry }\end{array}$ & $\begin{array}{l}\cdot \mathrm{CAB}+\mathrm{RPV} \\
\mathrm{Q}^{\mathrm{a}} \mathrm{W}^{\mathrm{a}}\end{array}$ & $\begin{array}{l}\text { - Primary: \% } \\
\text { participants } \\
\text { with HIV-1 } \\
\text { RNA } \geq 50 \\
\text { copies/mL } \\
\text { at Week } 48 \\
\text { - Key } \\
\text { secondary: } \\
\text { participants } \\
\text { with HIV-1 } \\
\text { RNA < 50 } \\
\text { copies/mL } \\
\text { at Week 48 }\end{array}$ \\
\hline \multicolumn{6}{|c|}{ a Participants with prior CAB + RPV LA exposure were excluded from the current analysis } \\
\hline \multicolumn{6}{|c|}{$\begin{array}{l}\text { 3TC, lamivudine; ABC, abacavir; ATLAS, Antiretroviral Therapy as Long-Acting Suppression; ATLAS- } \\
\text { 2M, ATLAS every } 2 \text { months; CAB, cabotegravir; cART, combination antiretroviral therapy; DTG, } \\
\text { dolutegravir; FLAIR, First Long-Acting Injectable Regimen; LA, long-acting; HIV-1, human } \\
\text { immunodeficiency virus type 1; PI, protease inhibitor; Q4W, every } 4 \text { weeks; Q8W, every } 8 \text { weeks; RNA, } \\
\text { ribonucleic acid; RPV, rilpivirine; SoC, standard of care }\end{array}$} \\
\hline
\end{tabular}

\section{Participants and treatments}

Eligible participants from the ATLAS, FLAIR, and ATLAS-2M trials were all treatment-experienced individuals with virologically suppressed HIV-1 infection, and a viral load of $<50$ HIV-1 ribonucleic acid (RNA) copies/mL. Participants from FLAIR, ATLAS and ATLAS-2M received oral lead-in therapy with $30 \mathrm{mg} C A B+25 \mathrm{mg}$ RPV once daily for four weeks before long-acting injectable was started to mitigate the risk of any serious side-effects associated with CAB or RPV before administering long acting injectable regimen. Participants in the ATLAS and ATLAS-2M trials had initiated treatment with any standard daily oral SoC prior to the switch to CAB + RPV LA $(14,15,17)$. Some participants in ATLAS-2M had prior CAB + RPV LA Q4W exposure; these participants were excluded from the current analysis, aiming for similarity in baseline participant characteristics as per ISPOR guidelines.

A pooled analysis of the ATLAS and FLAIR trials was previously conducted (16), and no significant heterogeneity between the two trials in terms of trial or participant characteristics for the treatment effect was found. Pooled data from ATLAS and FLAIR studies ( $n=591$ per treatment group), and data from 
participants with no prior CAB + RPV exposure ( $\mathrm{n}=327$ per treatment group) in the ATLAS-2M trial, were used to inform this analysis.

In addition, aiming to further satisfy the similarity assumption as per ISPOR guidelines, we explored comparability of participants' demographics and clinical characteristics at study entry between trials. Participants in the FLAIR trial had DTG-based induction therapy prior to the switch to CAB + RPV LA (14). Pooled data from the ATLAS and FLAIR trials, created overall data for CAB + RPV LA Q4W similar to the CAB + RPV LA Q4W arm of the ATLAS-2M trial (Fig. 1).

A summary of study population demographics and characteristics at baseline for the pooled ATLAS/FLAIR, and ATLAS-2M trials are shown in Table 2. Baseline characteristics between the Q4W arms of the pooled ATLAS/FLAIR and the ATLAS-2M trials showed no significant differences for sex, race, ethnicity, and body mass index ([BMI]; Table 2). A significant difference between treatment groups was found for both median age (ATLAS/FLAIR: 38 years; ATLAS-2M: 41 years; $P=0.0002$ ) and mean CD4 counts (ATLAS/FLAIR: 670.2, ATLAS-2M: 741.0; $\mathrm{P}=0.0004$ ); however, as per ISPOR guidelines on assessing similarity for indirect treatment comparisons, although researchers may be able to use statistical information they must rely primarily on clinical judgment of whether differences among studies may affect the comparisons of treatments or make some comparisons inappropriate (18). A mean difference (MD) in age of 3 years between treatment groups, although statistically significant, is very unlikely to be clinically relevant. Additionally, both ATLAS/FLAIR and ATLAS-2M participants had high CD4-cell count at baseline, both are within the range of a normal CD4-cell count, and therefore the differences are not considered clinically relevant. In addition, it was observed in the individual studies (ATLAS/FLAIR/ATLAS-2M) that efficacy outcomes per age group and CD4-cell count were consistent with the overall population, suggesting these factors were not effect modifiers in the clinical trials used in this comparison. The combined data for the ATLAS/FLAIR trials showed $65 \%$ of participants received INSTI treatment and $26 \%$ received NNRTIs at baseline; in contrast, data for the ATLAS-2M trial showed $42 \%$ of participants received INSTI treatment and $47 \%$ received NNRTIs at baseline (Table 2). Due to the marked difference between studies in baseline third agent, a subgroup analyses of virologic suppression and lack of virologic suppression stratified by baseline third active drug class were conducted to validate the findings of the main analysis. 
Table 2

Study population demographic characteristics at baseline for the ATLAS, FLAIR, pooled ATLAS/FLAIR and ATLAS-2M trials

\begin{tabular}{|c|c|c|c|c|c|}
\hline & \multicolumn{2}{|c|}{$\begin{array}{l}\text { ATLAS/FLAIR (14- } \\
\text { 16) }\end{array}$} & \multicolumn{2}{|c|}{ ATLAS-2M (17) } & \multirow{2}{*}{$\begin{array}{l}\begin{array}{l}\text { Statistical } \\
\text { comparison }\end{array} \\
\text { ATLAS/FLAIR vs } \\
\text { ATLAS-2M } \\
\text { CAB + RPV Q4W }\end{array}$} \\
\hline & $\begin{array}{l}\text { SoC } \\
(n= \\
591)\end{array}$ & $\begin{array}{l}\text { CAB + } \\
\text { RPV Q4W } \\
(n=591)\end{array}$ & $\begin{array}{l}\text { CAB + RPV } \\
\text { Q4W }^{\mathrm{a}} \\
(\mathrm{n}=327)\end{array}$ & $\begin{array}{l}\text { CAB + RPV } \\
Q^{2} W^{a} \\
(n=327)\end{array}$ & \\
\hline $\begin{array}{l}\text { Age (years), median } \\
\text { (range) }\end{array}$ & $\begin{array}{l}38(18, \\
82)\end{array}$ & $\begin{array}{l}38(19, \\
74)\end{array}$ & $42(19,67)$ & $41(20,83)$ & $P=0.0002^{b}$ \\
\hline Male, n (\%) & $\begin{array}{l}423 \\
(72)\end{array}$ & $429(73)$ & $252(77)$ & $254(78)$ & $P=0.1563^{c}$ \\
\hline Race, n (\%) & 408 & $430(73)$ & $256(78)$ & $238(73)$ & $P=0.0955^{d}$ \\
\hline White & & $109(18)$ & $45(14)$ & $57(17)$ & \\
\hline Black/African American & $(23)$ & $34(6)$ & $12(4)$ & $17(5)$ & \\
\hline Asian & $28(5)$ & $18(3)$ & $14(4)$ & $15(5)$ & \\
\hline Other & $20(3)$ & & & & \\
\hline Ethnicity & $74(13)$ & $63(11)$ & $42(13)$ & $54(17)$ & $P=0.3309^{c}$ \\
\hline \multicolumn{6}{|l|}{ Hispanic/Latino, n (\%) } \\
\hline BMI $\left(\mathrm{kg} / \mathrm{m}^{2}\right)$, mean (SD) & $\begin{array}{l}25.9 \\
(5.4)\end{array}$ & $25.7(4.8)$ & $26.2(5.2)$ & $26.2(5.1)$ & $P=0.1451^{b}$ \\
\hline $\begin{array}{l}\text { CD4-cell count } \\
\text { (cells/mm²), mean (SD) }\end{array}$ & $\begin{array}{l}670.2 \\
(273.2)\end{array}$ & $\begin{array}{l}672.7 \\
(264.3)\end{array}$ & $\begin{array}{l}741.0 \\
(288.8)\end{array}$ & $\begin{array}{l}688.6 \\
(266.0)\end{array}$ & $P=0.0004^{b}$ \\
\hline \multirow{2}{*}{$\begin{array}{l}\text { CD4-cell count } \\
(\text { cells/mm²), } n(\%)\end{array}$} & $54(9)$ & $42(7)$ & $17(5)$ & $25(8)$ & \multirow[t]{5}{*}{$P=0.0526^{d}$} \\
\hline & \multirow{4}{*}{$\begin{array}{l}117 \\
(20) \\
420 \\
(71)\end{array}$} & $120(20)$ & $49(15)$ & $60(18)$ & \\
\hline 800 & & 429 (73) & $261(80)$ & $242(74)$ & \\
\hline$\geq 350$ to $<500$ & & & & & \\
\hline$\geq 500$ & & & & & \\
\hline \multirow{2}{*}{$\begin{array}{l}\text { Baseline third active } \\
\text { class, } n(\%)\end{array}$} & \multirow{2}{*}{$\begin{array}{l}382 \\
(65)\end{array}$} & $385(65)$ & $141(43)$ & $136(42)$ & \multirow[t]{5}{*}{$P<0.0001^{d}$} \\
\hline & & $155(26)$ & $156(48)$ & $151(46)$ & \\
\hline & $\begin{array}{l}155 \\
(26)\end{array}$ & $51(9)$ & $30(9)$ & $40(12)$ & \\
\hline & $54(9)$ & & & & \\
\hline PI & & & & & \\
\hline
\end{tabular}




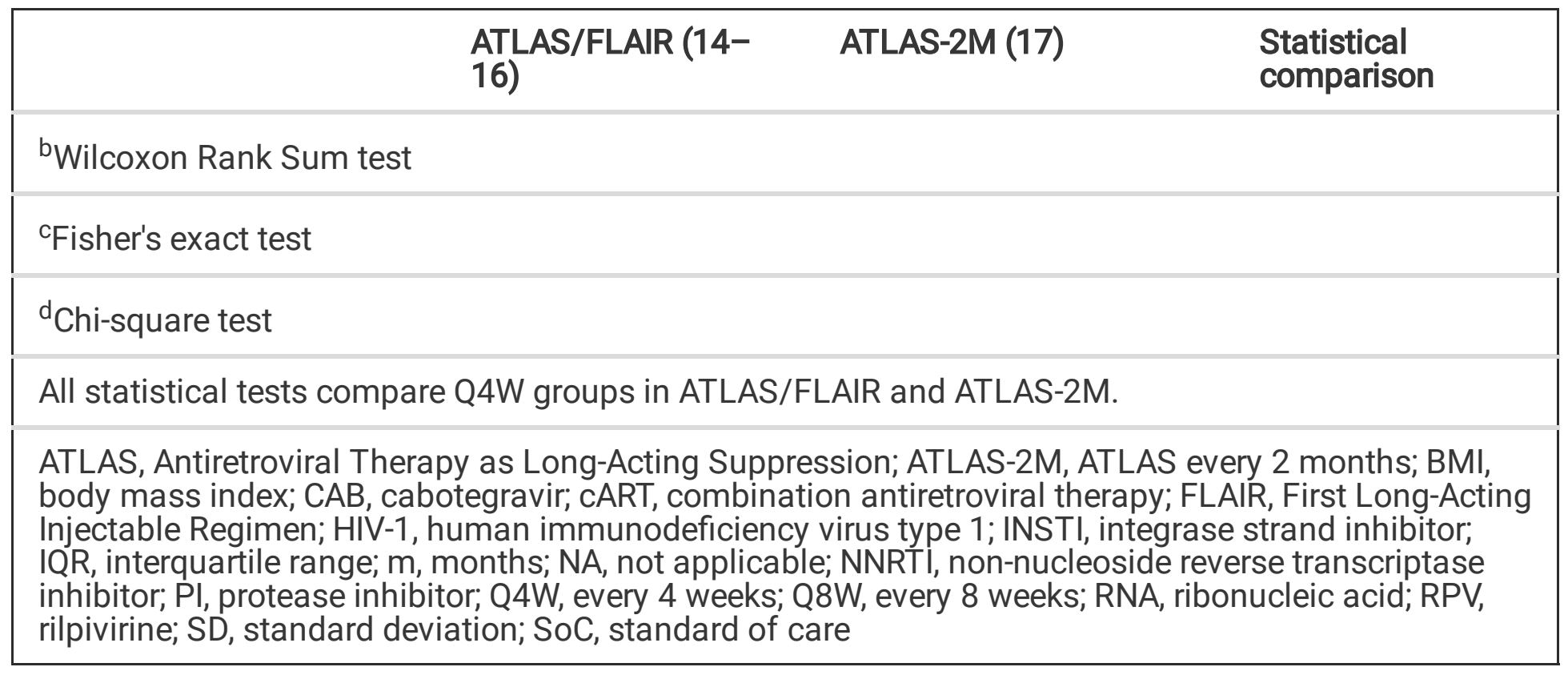

This study is a statistical analysis of data from the ATLAS, FLAIR and ATLAS-2M trials and therefore does not require approval from an institutional review board or ethics committee. All trials included in this study were conducted in accordance with the Declaration of Helsinki (20). All participants provided written informed consent and the protocols were approved by an institutional review board or ethics committee from each study site.

\section{Study measures}

The most frequently reported safety and efficacy outcomes were selected for quantitative comparison as follows: treatment efficacy was assessed for the primary study endpoint, the estimated proportion of participants with HIV-1 RNA $\geq 50$ copies/mL according to the FDA snapshot algorithm at Week 48. Other measures of treatment efficacy were assessed as key secondary endpoints: Week 48 virologic suppression (HIV-1 RNA $<50$ copies per $\mathrm{mL}$ ) as per FDA snapshot algorithm, CD4-cell count changes from baseline, and patients with no virologic data at Week 48. Safety was assessed in terms of discontinuations due to adverse events (AEs), and overall AEs, serious AEs, and Grade 3-5 AEs excluding injection-site reactions (ISRs) at Week 48. AEs were analyzed excluding ISRs to compare the events more likely related to systemic exposure to the respective drugs, rather than primarily to the route of administration. In the ATLAS/FLAIR and ATLAS-2M studies, ISRs for both Q4W and Q8W dosing were mostly mild (Grade 1 or 2) and the frequency progressively reduced to Week 48 among study participants, resulting in very few $(<2 \%)$ discontinuations, which are included in the discontinuations due to AEs analysis. Comparative efficacy of virologic suppression and lack of virologic suppression were stratified by baseline third active drug class (INSTI, NNRTI, and protease inhibitor [PI]) in a subgroup analysis to assess the relative effects of each treatment class and whether any statistically significant differences that can impact overall outcomes exist.

\section{Statistical analyses}


Assessment of the similarity of population demographic characteristics at baseline and effect of the baseline third active drug class on efficacy, determined by the percentage of $<50 \mathrm{HIV}-1$ copies $/ \mathrm{mL}$ in the Q4W arms of the pooled ATLAS/FLAIR trials and ATLAS-2M was carried out using the Wilcoxon Rank Sum Test and the Fisher's Exact Test. The robustness of comparative efficacy conclusions was assessed using alternate summary statistics. Between treatment comparison statistics for ATLAS/FLAIR (Q4W vs SoC) and for ATLAS-2M (Q8W vs Q4W) are shown in Supplementary Table S1.

The statistical methodology published by Bucher et al (19) was then used to calculate relative risk (RR), odds ratio (OR), and risk difference (RD) for the comparison of CAB + RPV LA Q8W versus daily oral SoC, using CAB + RPV Q4W as the common comparator. In this method, a summary statistic of the comparison is expressed on a continuous scale and assumed to have a normal distribution. The MD and RD scales are assumed to be and were normally distributed. The OR and RR scales were transformed to a normally distributed scale using the natural log transformation (InOR or InRR). Thus, we have:

Indirect treatment effect $[Q 8 \mathrm{~W}-\mathrm{SoC}]$

$$
\begin{aligned}
& =\llbracket \ln O R / \ln R R / R D / M D \rrbracket[Q 8 W-Q 4 W] A T L A S-2 M-\llbracket \ln O R \\
& / \ln R R / R D / M D \rrbracket[Q 4 W-S O C] A T L A S+F L A I R
\end{aligned}
$$

Standard errors $(S E)$

$$
=\sqrt{ }\left(S E_{-}\left(\ln O R / \ln R R / R D / M D_{-} A T L A S-2 M^{2}+S E(\ln O R / \ln R R / R D / M D)^{2}\right)\right)
$$

\section{Results}

\section{Main analysis}

A summary of 48-week efficacy and safety data from the pooled ATLAS/FLAIR and ATLAS-2M trials used for the indirect treatment comparison is shown in Table 3. Over $90 \%$ of participants in all four arms of the pooled ATLAS/FLAIR and ATLAS-2M trials achieved $<50$ copies/mL of HIV-1 RNA at 48 weeks. All four treatment groups in ATLAS/FLAIR and ATLAS-2M reported a $2 \%$ rate of HIV- 1 RNA $\geq 50$ copies $/ \mathrm{mL}$. The percentage of patients with no virologic data at Week 48 was $<7 \%$ across all four treatment groups.

Discontinuations due to AEs, including ISRs occurred in fewer than $5 \%$ of participants across all trials and treatment arms. Changes from baseline at Week 48, in mean CD4-cell count were small across all trials and treatment arms ( -19.2 to 48.2 cells $/ \mu \mathrm{L})$. Overall AEs excluding ISRs occurred in a similar percentage of participants receiving CAB + RPV Q4W in the pooled ATLAS/FLAIR and ATLAS-2M trials ( $86.3 \%$ vs $86.2 \%$, respectively). Likewise, the percentages of participants receiving SoC and CAB + RPV Q8W who experienced AEs excluding ISRs were similar (75.3\% vs $77.7 \%$, respectively). Serious AEs excluding ISRs occurred in approximately $5 \%$ or fewer and Grade 3-5 AEs occurred in $8 \%$ or fewer of participants across all trials and arms. 
Table 3

Summary of 48-week efficacy and safety data from the pooled ATLAS/FLAIR and ATLAS-2M trials considered for the indirect treatment comparison (full analysis set)

\begin{tabular}{|c|c|c|c|c|}
\hline & \multicolumn{2}{|c|}{$\begin{array}{l}\text { ATLAS/FLAIR (14- } \\
\text { 16) }\end{array}$} & \multicolumn{2}{|l|}{ ATLAS-2M (17) } \\
\hline & $\begin{array}{l}\text { SOC } \\
(n= \\
591)\end{array}$ & $\begin{array}{l}\text { CAB + } \\
\text { RPV Q4W } \\
(n=591)\end{array}$ & $\begin{array}{l}\mathrm{CAB}+\mathrm{RPV} \\
\mathrm{Q}^{\mathrm{a}} \mathrm{W}(\mathrm{n}=327)\end{array}$ & $\begin{array}{l}C A B+R P V \\
Q 8 W^{\mathrm{a}}(n=327)\end{array}$ \\
\hline $\begin{array}{l}\text { HIV-1 RNA } \\
<50 \text { copies/mL, n (\%) }\end{array}$ & $\begin{array}{l}558 \\
(94.4)\end{array}$ & $\begin{array}{l}550 \\
(93.1)\end{array}$ & $300(91.7)$ & $306(93.6)$ \\
\hline $\begin{array}{l}\text { HIV-1 RNA } \\
\geq 50 \text { copies } / \mathrm{mL}, \mathrm{n}(\%)^{\mathrm{b}}\end{array}$ & $\begin{array}{l}10 \\
(1.7)\end{array}$ & $11(1.9)$ & $5(1.5)$ & $5(1.5)$ \\
\hline $\begin{array}{l}\text { CD4-cell count (cells/ } / \text { l), mean (SD) } \\
\text { change from baseline }\end{array}$ & $\begin{array}{l}48.2 \\
(182.1)\end{array}$ & $\begin{array}{l}24.5 \\
(191.3)\end{array}$ & $-19.2(204.9)$ & $-0.7(150.6)$ \\
\hline No virologic data at week $48^{c}, n(\%)^{b}$ & $\begin{array}{l}23 \\
(3.9)\end{array}$ & $30(5.1)$ & $22(6.7)$ & $16(4.9)$ \\
\hline Discontinuation due to AEs, $n(\%)^{d}$ & $7(1.2)$ & $19(3.2)$ & $11(3.4)$ & $6(1.8)$ \\
\hline Any AE (excluding ISR), n (\%) & $\begin{array}{l}445 \\
(75.3)\end{array}$ & $\begin{array}{l}510 \\
(86.3)\end{array}$ & $282(86.2)$ & $254(77.7)$ \\
\hline Serious AEs (excluding ISR), n (\%) & $\begin{array}{l}26 \\
(4.4)\end{array}$ & $31(5.2)$ & $11(3.4)$ & $16(4.9)$ \\
\hline $\begin{array}{l}\text { Grade 3-5 AEs (excluding ISR) } \\
\text { maintenance phase }\end{array}$ & $\begin{array}{l}35 \\
(5.9)\end{array}$ & $47(8.0)$ & $20(6.1)$ & $16(4.9)$ \\
\hline \multicolumn{5}{|c|}{ a Participants with prior CAB + RPV LA exposure were excluded } \\
\hline \multicolumn{5}{|l|}{${ }^{b}$ As per the FDA snapshot algorithm } \\
\hline \multicolumn{5}{|c|}{$\begin{array}{l}\text { c These include discontinuations due to AEs and other reasons such as: lost to follow-up, protocol } \\
\text { deviations, investigator decision, lack of efficacy etc. }\end{array}$} \\
\hline \multicolumn{5}{|c|}{ dThese include participants with no virologic data at Week 48 who discontinued due to AEs. } \\
\hline \multicolumn{5}{|c|}{$\begin{array}{l}\text { AE, adverse event; ATLAS, Antiretroviral Therapy as Long-Acting Suppression; ATLAS-2M, ATLAS } \\
\text { every } 2 \text { months; CAB, cabotegravir; FLAIR, First Long-Acting Injectable Regimen; HIV-1, human } \\
\text { immunodeficiency virus type 1; ISR, injection-site reaction; Q4W, every } 4 \text { weeks; Q8W, every } 8 \text { weeks; } \\
\text { RNA, ribonucleic acid; RPV, rilpivirine; SD, standard deviation; SoC, standard of care }\end{array}$} \\
\hline
\end{tabular}

Results of the indirect comparison of CAB + RPV LA Q8W with daily oral SoC are summarized in Fig. 2A and Table 4. The efficacy outcomes analyzed were virologic suppression (HIV-1 RNA $<50$ copies $/ \mathrm{mL}$ ), HIV-1 RNA $\geq 50$ copies/mL, no virologic data at Week 48, and change from baseline in CD4-cell count. 
There were no statistically significant differences in any of the key efficacy outcomes analyzed for CAB + RPV LA Q8W compared with daily oral SoC at Week 48. Similarly, there were no statistically significant differences in any safety outcome analyzed, discontinuations due to AEs, and any AEs, serious AEs, and Grade 3-5 AEs not related to ISRs, for CAB + RPV LA Q8W compared with daily oral SoC at Week 48. This was consistent across all comparative effect measures assessed, including RR, OR, and RD, and MD for CD4-cell count change from baseline. 
Table 4

Summary of results of the indirect comparison of CAB + RPV LA Q8W relative to SoC

\begin{tabular}{|c|c|c|c|}
\hline & \multicolumn{3}{|c|}{ Comparative effect measure $(95 \% \mathrm{Cl})$} \\
\hline & $\begin{array}{l}\text { Relative } \\
\text { risk }\end{array}$ & $\begin{array}{l}\text { Risk difference, } \\
\%\end{array}$ & Odds ratio \\
\hline \multirow[t]{2}{*}{ HIV-1 RNA < 50 copies/mL at Week 48} & 1.01 & 0.5 & 1.04 \\
\hline & $(0.95,1.06)$ & $(-4.40,5.3)$ & $(0.49,2.22)$ \\
\hline \multirow[t]{2}{*}{ HIV-1 RNA $\geq 50$ copies/mL at Week 48} & 1.10 & 0.2 & 1.10 \\
\hline & $(0.25,4.90)$ & $(-2.20,2.60)$ & $(0.24,5.03)$ \\
\hline \multirow{2}{*}{$\begin{array}{l}\text { CD } 4 \text { cell count change from baseline, per } \mu L^{a} \text { at } \\
\text { Week } 48\end{array}$} & - & -5.1 & - \\
\hline & & $(-40.0,29.7)$ & \\
\hline \multirow[t]{2}{*}{ No virologic data at Week 48} & 0.95 & -0.7 & 0.94 \\
\hline & $(0.42,2.15)$ & $(-4.90,3.60)$ & $(0.40,2.24)$ \\
\hline \multirow[t]{2}{*}{ Discontinuations due to AEs at Week 48} & 1.48 & 0.5 & 1.49 \\
\hline & $(0.40,5.46)$ & $(-2.5,3.5)$ & $(0.39,5.65)$ \\
\hline \multirow[t]{2}{*}{ Any AE (excluding ISR) maintenance phase } & 1.03 & 2.4 & 1.15 \\
\hline & $(0.94,1.13)$ & $(-4.90,9.80)$ & $(0.69,1.90)$ \\
\hline \multirow[t]{2}{*}{ Serious AE (excluding ISR) maintenance phase } & 1.73 & 2.4 & 1.78 \\
\hline & $(0.73,4.11)$ & $(-1.50,6.3)$ & $(0.72,4.40)$ \\
\hline \multirow[t]{2}{*}{ Grade 3-5 AEs (excluding ISR) maintenance phase } & 1.68 & 3.3 & 1.74 \\
\hline & $(0.78,3.61)$ & $(-1.3,7.8)$ & $(0.77,3.92)$ \\
\hline \multicolumn{4}{|c|}{ HIV-1 RNA $<50$ copies/mL at Week 48 by baseline third active drug class } \\
\hline \multirow[t]{2}{*}{ INSTI } & 1.04 & 3.8 & 1.62 \\
\hline & $(0.96,1.13)$ & $(-3.6,11.2)$ & $(0.57,4.60)$ \\
\hline \multirow[t]{2}{*}{ NNRTI } & 0.96 & -4.0 & 0.50 \\
\hline & $(0.89,1.04)$ & $(-11.4,3.3)$ & $(0.13,1.99)$ \\
\hline \multicolumn{4}{|l|}{${ }^{\mathrm{a}}$ Mean difference } \\
\hline \multicolumn{4}{|c|}{ bValues could not be calculated for RR and OR as value for SoC in ATLAS/FLAIR was 0} \\
\hline \multicolumn{4}{|c|}{$\begin{array}{l}\text { AE, adverse event; CAB, cabotegravir; } \mathrm{Cl} \text {, confidence interval; HIV-1, human immunodeficiency virus } \\
\text { type 1; INSTI, integrase strand inhibitor, ISR, injection-site reaction; NNRTI, non-nucleoside reverse } \\
\text { transcriptase inhibitor; PI, protease inhibitor; Q8W, every } 8 \text { weeks; RNA, ribonucleic acid; RPV, rilpivirine; } \\
\text { SoC, standard of care }\end{array}$} \\
\hline
\end{tabular}




\begin{tabular}{|c|c|c|c|}
\hline & \multicolumn{3}{|c|}{ Comparative effect measure $(95 \% \mathrm{Cl})$} \\
\hline & $\begin{array}{l}\text { Relative } \\
\text { risk }\end{array}$ & $\begin{array}{l}\text { Risk difference, } \\
\%\end{array}$ & Odds ratio \\
\hline \multirow[t]{2}{*}{ PI } & 1.01 & 1.0 & 0.96 \\
\hline & $(0.83,1.24)$ & $(-17.0,19.1)$ & $(0.11,8.12)$ \\
\hline \multicolumn{4}{|c|}{ HIV-1 RNA $\geq 50$ copies/mL at week 48 by baseline third active drug class } \\
\hline \multirow[t]{2}{*}{ INSTI } & 1.03 & 0 & 1.03 \\
\hline & $(0.13,7.97)$ & $(-3.7,3.7)$ & $(0.13,8.27)$ \\
\hline \multirow[t]{2}{*}{ NNRTI } & 2.07 & 1.3 & 2.09 \\
\hline & $\begin{array}{l}(0.08 \\
52.49)\end{array}$ & $(-2.2,4.9)$ & $\begin{array}{l}(0.08, \\
54.86)\end{array}$ \\
\hline \multirow[t]{2}{*}{$\mathrm{PI}^{\mathrm{b}}$} & - & 1.1 & - \\
\hline & & $(-7.8,10.0)$ & \\
\hline \multicolumn{4}{|c|}{${ }^{a}$ Mean difference } \\
\hline \multicolumn{4}{|c|}{ bValues could not be calculated for RR and OR as value for SoC in ATLAS/FLAIR was 0} \\
\hline \multicolumn{4}{|c|}{$\begin{array}{l}\text { AE, adverse event; } \mathrm{CAB} \text {, cabotegravir; } \mathrm{Cl} \text {, confidence interval; HIV-1, human immunodeficiency virus } \\
\text { type 1; INSTI, integrase strand inhibitor; ISR, injection-site reaction; NNRTI, non-nucleoside reverse } \\
\text { transcriptase inhibitor; PI, protease inhibitor; Q8W, every } 8 \text { weeks; RNA, ribonucleic acid; RPV, rilpivirine; } \\
\text { SoC, standard of care }\end{array}$} \\
\hline
\end{tabular}

\section{Subgroup analysis}

The CAB + RPV LA Q8W versus daily oral SoC virologic suppression comparisons were stratified by baseline third active drug class to understand the potential impact on the study conclusions of the unmatched distribution of participants switching from INSTIs and NNRTIs to study treatment between the pooled ATLAS/FLAIR and ATLAS-2M trials ( $65 \%$ vs $42 \%$ of participants received INSTI, and $26 \%$ vs and $47 \%$ received NNRTIs in the trials, respectively). Comparative effect measures consistently showed no statistically significant differences in virologic suppression or lack of virologic suppression for any of the baseline third active drug classes assessed (Table 4; Fig. 2B and 2C). This suggests that baseline third active drug class does not impact the findings of the main analysis.

\section{Discussion}

Previous research has established the non-inferiority of CAB + RPV LA Q4W in the maintenance of virologic suppression compared with daily oral SoC (ATLAS and FLAIR) $(14,15)$, as well as the noninferiority of CAB + RPV LA Q8W compared with Q4W dosing (ATLAS-2M) (17). To date, however, there have been no randomized clinical trials comparing the efficacy and safety of CAB + RPV LA Q8W with 
daily oral SoC ART in virologically suppressed PLHIV on maintenance treatment regimens. The current analysis indirectly compared 48-week treatment outcomes between CAB + RPV LA Q8W with daily oral SoC ART, showing that there are no statistically significant differences in key efficacy or safety outcomes, across all comparative effect measures assessed. The results of the current analysis, therefore, suggest that CAB + RPV LA Q8W is comparable to daily oral SoC in terms of expected efficacy and key safety outcomes.

While indirect comparisons provide useful insights, they cannot replace evidence from head-to-head studies, which remain the gold standard. In the absence of a head-to-head study, this indirect comparison can be used to compare treatment outcomes across studies, supporting decisions about best choices for ART treatment (21). A head-to-head study assessing non-inferiority in efficacy of CAB + RPV Q8W versus bictegravir/emtricitabine/tenofovir alafenamide is currently planned and if successful will validate the findings of this analysis. It is important to appreciate the limitations of indirect comparisons, such as how clinically and methodologically similar the trials being compared are. This can be assessed statistically, but also requires clinical judgment to determine whether differences among studies may affect the clinical interpretation of such comparisons (18). In the current analysis, there was an unmatched distribution of participants switching from INSTIs and NNRTIs to study treatment between the pooled ATLAS/FLAIR and ATLAS-2M trials, which had the potential to be clinically relevant. Therefore, a subgroup analysis on virologic suppression was carried out to assess any potential effects of this unmatched distribution. The subgroup analysis found that there were no statistically significant differences on virologic suppression or lack of virologic suppression for any of the baseline third active drug classes assessed, implying that the overall conclusions of the main analyses are robust and unaffected by differences in baseline third active drug class across trials. The findings of the indirect comparisons made in this study should nonetheless be interpreted with caution due to the general limitations associated with this type of comparison.

More convenient regimens with less frequent dosing requirements will help address some of the remaining challenges related to antiretroviral treatment, including suboptimal adherence, HIV-related stigma, and the need for daily dosing $(16,22-26)$. Adherence to antiretroviral therapy (ART) for patients with HIV-1 is essential to achieve durable clinical outcomes, and minimize drug resistance and lack of virologic suppression (4). Even with one pill a day, adherence is less than optimal, over one quarter of PLHIV on ART experience episodes of non-adherence (27-29). Surveys conducted in the United States have shown that for populations including people who inject drugs and PLHIV with adherence issues there is great interest in switching to treatments with less frequent dosing $(27,30-32)$. A recent international survey found that although general satisfaction with daily ART was high, there were still a number of emotional challenges associated with it, including the stress and pressure of taking medication at the right time every day, concealment of HIV medication, daily treatment being a constant reminder of HIV status, and treatment disrupting and limiting daily life (33). Furthermore, the long-acting attribute was ranked among the most valued treatment attributes, second only to long-term safety concerns and adverse events (34). The results of the present analysis suggest that CAB + RPV LA dosed every 8 weeks is non-inferior to current SoC oral ART in maintaining HIV viral suppression. Given the 
preference of participants in the ATLAS-2M study for the Q8W dosing regimen, this treatment regimen appears to offer a promising future option for long-term successful ART (17).

\section{Conclusion}

Long-acting injectable CAB + RPV dosed Q8W showed no statistically significant differences in terms of efficacy and safety compared with current HIV Treatment Guideline-recommended daily oral cART regimens in treatment-experienced, virologically suppressed PLHIV. This analysis supports the therapeutic potential of CAB + RPV LA Q8W for PLHIV who seek an alternative maintenance treatment option to daily oral SoC.

\section{Abbreviations}

$\mathrm{AE}$, adverse events

ATLAS, Antiretroviral Therapy as Long-Acting Suppression

ATLAS-2M, Antiretroviral Therapy as Long-Acting Suppression every 2 months

$\mathrm{BMI}$, body mass index

$\mathrm{CAB}$, cabotegravir

cART, combination antiretroviral therapy

DTG, dolutegravir

FLAIR, First Long-Acting Injectable Regimen

HIV-1, human immunodeficiency virus type 1

INSTI, integrase strand inhibitor

ISPOR, International Society for Pharmacoeconomics and Outcomes Research

ISR, injection-site reaction

MD, mean difference

NRTI, nucleoside/nucleotide reverse transcriptase inhibitor

NNRTI, non-nucleoside reverse transcriptase inhibitor

OR, odds ratio

PLHIV, people living with HIV 
Pl, protease inhibitor

Q4W, every 4 weeks

Q8W, every 8 weeks

$\mathrm{RD}$, risk difference

RNA, ribonucleic acid

$\mathrm{RPV}$, rilpivirine

$\mathrm{RR}$, relative risk

SoC, standard of care

\section{Declarations}

\section{Ethics approval and consent to participate}

This study is a statistical analysis of data from the ATLAS, FLAIR and ATLAS-2M trials and therefore does not require approval from an institutional review board or ethics committee. The FLAIR, ATLAS and ATLAS-2M trials were all conducted in accordance with the Declaration of Helsinki. All participants provided written informed consent and the protocols were approved by an institutional review board or ethics committee from each study site.

\section{Consent for publication}

Not applicable

\section{Availability of data and materials}

- All data generated or analyzed during this study are included in this published article [and its supplementary information files].

\section{Competing interests}

VC and NV are employees of ViiV Healthcare. SW is employee of GlaxoSmithKline and owns stocks/shares. SJS is an employee of Pharmerit- an OPEN Health Company, paid consultants to ViiV Healthcare.

\section{Funding}


This study was funded by ViiV Healthcare who participated in the design of the study and in the gathering, analysis, and interpretation of the data.

\section{Authors' contributions}

VC, SJS, SW and NV contributed to the conception and design of the study, data acquisition, data analysis and interpretation, and read and approved the final manuscript. All authors reviewed the manuscript critically for important intellectual content, gave final approval of the version to be published, and agreed to be accountable for all aspects of the work.

\section{Acknowledgments}

Editorial support (in the form of writing assistance, assembling figures, collating author comments, grammatical editing, and referencing) was provided by Laura Whiteley, at Fishawack Indicia Ltd, UK, and was funded by ViiV Healthcare.

\section{References}

1. Adolescents PoAGfAa. Guidelines for the Use of Antiretroviral Agents in Adults and Adolescents with HIV. Department of Health and Human Services Weblink: http://www.aidsinfo.nih.gov/ContentFiles/AdultandAdolescentGL.pdf (Accessed May 2020) 2019 [.

2. Saag MS, Benson CA, Gandhi RT, Hoy JF, Landovitz RJ, Mugavero MJ, et al. Antiretroviral Drugs for Treatment and Prevention of HIV Infection in Adults: 2018 Recommendations of the International Antiviral Society-USA Panel. JAMA. 2018;320(4):379-96.

3. EACS Guidelines Version. 102019 [Available from: https://www.eacsociety.org/files/2019_guidelines-10.0_final.pdf.

4. Kangethe A, Polson M, Lord TC, Evangelatos T, Oglesby A. Real-World Health Plan Data Analysis: Key Trends in Medication Adherence and Overall Costs in Patients with HIV. J Manag Care Spec Pharm. 2019;25(1):88-93.

5. Sax PE, Meyers JL, Mugavero M, Davis KL. Adherence to antiretroviral treatment and correlation with risk of hospitalization among commercially insured HIV patients in the United States. PLoS One. 2012;7(2):e31591.

6. Sutton SS, Hardin JW, Bramley TJ, D'Souza AO, Bennett CL. Single- versus multiple-tablet HIV regimens: adherence and hospitalization risks. Am J Manag Care. 2016;22(4):242-8.

7. Wood B, Spach D. Switching or Simplifying Antiretroviral Therapy Weblink: https://cdn.hiv.uw.edu/pdf/antiretroviral-therapy/switching-antiretroviral-therapy/core-concept/all (Accessed May 2020) 2019 [. 
8. Chawla A, Wang C, Patton C, Murray M, Punekar Y, de Ruiter A, et al. A Review of Long-Term Toxicity of Antiretroviral Treatment Regimens and Implications for an Aging Population. Infectious diseases therapy. 2018;7(2):183-95.

9. 9.

10. 10 .

11. Krentz HB, Gill MJ. The Impact of Non-Antiretroviral Polypharmacy on the Continuity of Antiretroviral Therapy (ART) Among HIV Patients. AIDS Patient Care STDs. 2016;30(1):11-7.

12. Zhou S, Martin K, Corbett A, Napravnik S, Eron J, Zhu Y, et al. Total daily pill burden in HIV-infected patients in the southern United States. AIDS Patient Care STDs. 2014;28(6):311-7.

13. Carvalho PP, Barroso SM, Coelho HC, Penaforte FRO. Factors associated with antiretroviral therapy adherence in adults: an integrative review of literature. Ciencia saude coletiva. 2019;24(7):2543-55.

14. Orkin C, Arasteh K, Gorgolas Hernandez-Mora M, Pokrovsky V, Overton ET, Girard PM, et al. LongActing Cabotegravir and Rilpivirine after Oral Induction for HIV-1 Infection. N Engl J Med. 2020;382(12):1124-35.

15. Swindells S, Andrade-Villanueva JF, Richmond GJ, Rizzardini G, Baumgarten A, Masia M, et al. LongActing Cabotegravir and Rilpivirine for Maintenance of HIV-1 Suppression. N Engl J Med. 2020;382(12):1112-23.

16. Overton ET, Orkin C, Swindells S, Arasteh K, Górgolas Hernández-Mora M, Pokrovsky V, et al. Monthly long-acting cabotegravir and rilpivirine is non-inferior to oral ART as maintenance therapy for HIV-1 infection: Week 48 pooled analysis from the Phase 3 ATLAS and FLAIR studies. 10th IAS Conference on HIV Science; Mexico City, Mexico2019.

17. Overton ET, Richmond GJ, Rizzardini G, Jaeger H, Orrell C, Nagimova F, et al. Cabotegravir + rilpivirine every 2 months is noninferior to monthly: ATLAS-2M study. Conference on retroviruses and opportunistic infections; Boston, Massachusetts, USA2020.

18. Hoaglin DC, Hawkins N, Jansen JP, Scott DA, Itzler R, Cappelleri JC, et al. Conducting indirecttreatment-comparison and network-meta-analysis studies: report of the ISPOR Task Force on Indirect Treatment Comparisons Good Research Practices: part 2. Value Health. 2011;14(4):429-37.

19. Bucher HC, Guyatt GH, Griffith LE, Walter SD. The results of direct and indirect treatment comparisons in meta-analysis of randomized controlled trials. J Clin Epidemiol. 1997;50(6):683-91.

20. World Medical Association Declaration. of Helsinki: ethical principles for medical research involving human subjects. Jama. 2013;310(20):2191-4.

21. Jansen JP, Fleurence R, Devine B, Itzler R, Barrett A, Hawkins N, et al. Interpreting indirect treatment comparisons and network meta-analysis for health-care decision making: report of the ISPOR Task Force on Indirect Treatment Comparisons Good Research Practices: part 1. Value Health. 2011;14(4):417-28.

22. Eaton EF, McDavid C, Banasiewicz MK, Mugavero MJ, Knight SJ. Patient preferences for antiretroviral therapy: effectiveness, quality of life, access and novel delivery methods. Patient Prefer Adherence. 2017;11:1585-90. 
23. Philbin MM, Parish CL, Kinnard EN, Reed SE, Kerrigan D, Alcaide ML, et al Multisite Study of Women Living With HIV's Perceived Barriers to, and Interest in, Long-Acting Injectable Antiretroviral Therapy. Journal of acquired immune deficiency syndromes (1999). 2020;84(3):263 - 70.

24. Paramesha AE, Chacko LK. Predictors of adherence to antiretroviral therapy among PLHIV. Indian J Public Health. 2019;63(4):367-76.

25. Priest JL, Burton T, Blauer-Peterson C, Andrade K, Oglesby A. Clinical characteristics and treatment patterns among US patients with HIV. Am J Manag Care. 2019;25(12):580-6.

26. Langebeek N, Gisolf EH, Reiss P, Vervoort SC, Hafsteinsdóttir TB, Richter C, et al. Predictors and correlates of adherence to combination antiretroviral therapy (ART) for chronic HIV infection: a metaanalysis. BMC Med. 2014;12:142.

27. Rana Al, Castillo-Mancilla JR, Tashima KT, Landovitz RL. Advances in Long-Acting Agents for the Treatment of HIV Infection. Drugs. 2020;80(6):535-45.

28. Gardner EM, McLees MP, Steiner JF, Del Rio C, Burman WJ. The spectrum of engagement in HIV care and its relevance to test-and-treat strategies for prevention of HIV infection. Clinical infectious diseases: an official publication of the Infectious Diseases Society of America. 2011;52(6):793-800.

29. Powers KA, Samoff E, Weaver MA, Sampson LA, Miller WC, Leone PA, et al Longitudinal HIV Care Trajectories in North Carolina. Journal of acquired immune deficiency syndromes (1999). 2017;74 Suppl 2(Suppl 2):S88-S95.

30. Jacobson JM, Flexner CW. Universal antiretroviral regimens: thinking beyond one-pill-once-a-day. Curr Opin HIV AIDS. 2017;12(4):343-50.

31. Weld ED, Rana MS, Dallas RH, Camacho-Gonzalez AF, Ryscavage P, Gaur AH, et al Interest of Youth Living With HIV in Long-Acting Antiretrovirals. Journal of acquired immune deficiency syndromes (1999). 2019;80(2):190-7.

32. Williams J, Sayles HR, Meza JL, Sayre P, Sandkovsky U, Gendelman HE, et al. Long-acting parenteral nanoformulated antiretroviral therapy: interest and attitudes of HIV-infected patients. Nanomedicine (London England). 2013;8(11):1807-13.

33. Young B, Marcotullio S, Punekar Y, Koteff J, Ustianowski A, De los Rios P, et al. Experiences and Emotional Challenges of Antiretroviral Treatment - Findings from the Positive Perspectives Study [Poster 1329]. Open Forum Infect Dis. 2019;6(Suppl 1):481.

34. Young B, Spire B, Morcillo DG, Muchenje M, Parkinson K, Krehl M, et al. Patient Experience and Views on Antiretroviral Treatment-Findings from the Positive Perspectives Survey [Poster 1393]. Open Forum Infect Dis. 2017;4(Suppl 1):431-S2.

35. ClinicalTrials.gov. Efficacy, Safety and Tolerability Study of Long-acting Cabotegravir Plus Longacting Rilpivirine (CAB LA + RPV LA) in Human-immunodeficiency Virus-1 (HIV-1) Infected Adults [Available from: https://clinicaltrials.gov/ct2/show/NCT03299049.

\section{Figures}




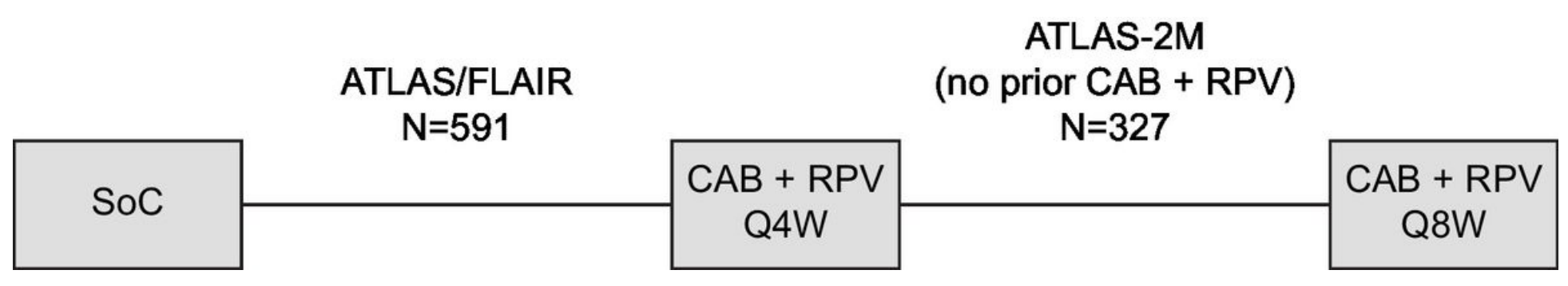

\section{Figure 1}

Diagram of studies included in indirect comparison CAB, cabotegravir; Q4W, every 4 weeks; Q8W, every 8 weeks; RPV, rilpivirine; SoC, standard of care 


\section{Outcome}

HIV-1 RNA $<50$ copies/mL

HIV-1 RNA $\geq 50$ copies/mL

CD4 cell count change

from baseline, per $\mu \mathrm{L}^{\mathrm{a}, \mathrm{b}}$

No virologic data at Week $48^{\mathrm{a}, \mathrm{c}}$

Discontinuations due to $\mathrm{AEs}$

Any AE (excluding ISR)

Serious AE (excluding ISR)

Grade 3-5 AEs (excluding ISR)

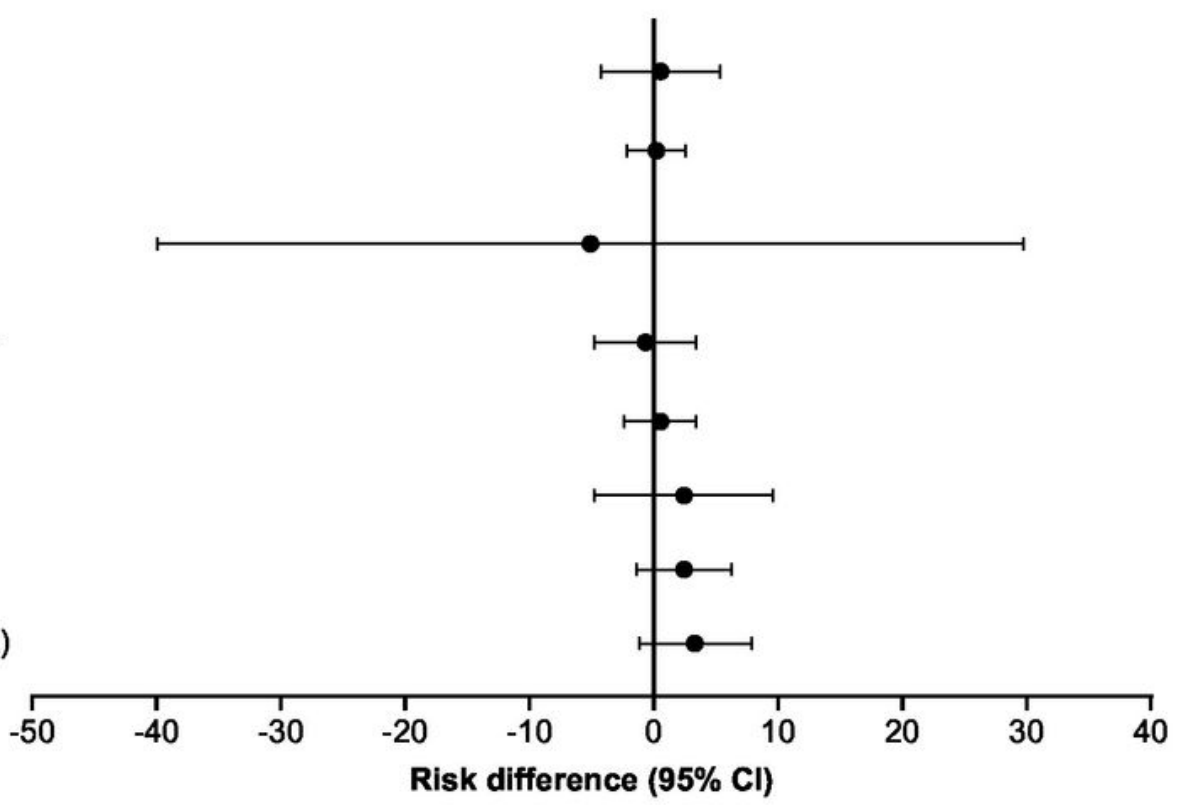

Risk difference

(95\% Cl)

$0.5(-4.4,5.3)$

$0.2(-2.2,2.6)$

$-5.1(-40.0,29.7)$

$-0.7(-4.7,4.7)$

$0.5(-2.5,3.5)$

$2.4(-4.9,9.8)$

$2.4(-1.5,6.3)$

$3.3(-1.3,7.8)$

\section{Risk difference $(95 \% \mathrm{Cl})$}

B.

Baseline third active drug class

INSTI

NNRTI

PI

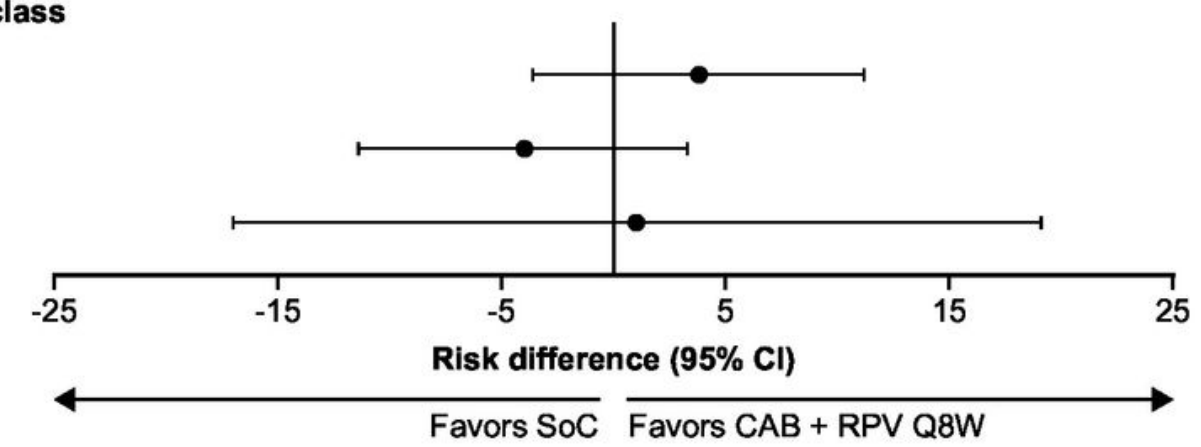

Risk difference

$(95 \% \mathrm{Cl})$

$3.8(-3.6,11.2)$

$-4.0(-11.4,3.3)$

$1.0(-17.0,19.1)$

Favors SoC Favors CAB + RPV Q8W

C.

Baseline third active drug class

INSTI

NNRTI

PI

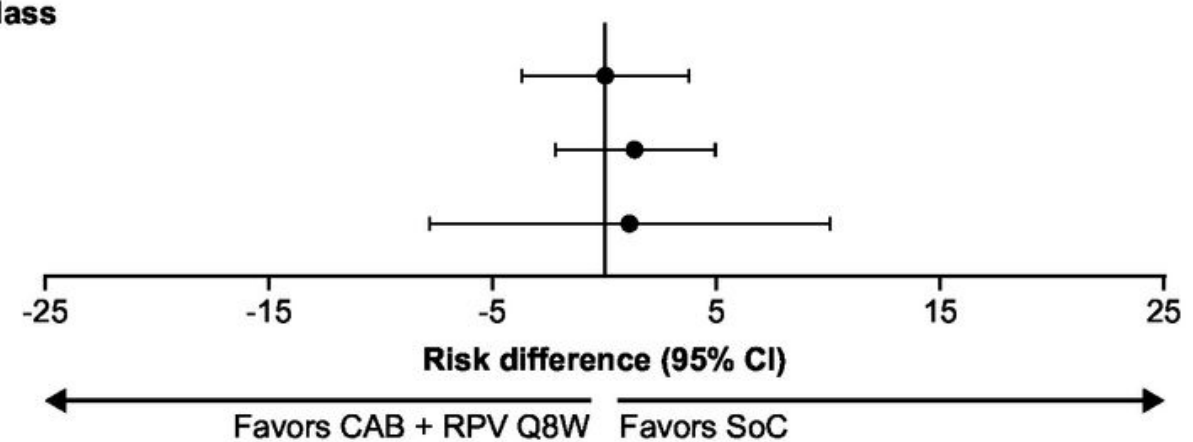

Risk difference

$(95 \% \mathrm{Cl})$

$0.0(-3.7,3.7)$

$1.3(-2.2,4.9)$

$1.1(-7.8,10.0)$

Favors CAB + RPV Q8W Favors SoC

Figure 2

Summary of risk difference results of the indirect comparison of CAB + RPV LA Q8W relative to SoC A) by outcome, B) virologic suppression (HIV RNA $<50$ copies/mL as per FDA snapshot algorithm) results stratified by baseline third active drug class, and C) lack of virologic suppression (HIV $\geq 50 \mathrm{copies} / \mathrm{mL}$ as per FDA Snapshot Algorithm) results stratified by baseline third active drug class aFavors CAB + RPV Q8W bMean difference; cValues could not be calculated for RR and OR as value for SoC in ATLAS/FLAIR 
was $0 \mathrm{AE}$, adverse event; $\mathrm{CAB}$, cabotegravir; $\mathrm{Cl}$, confidence interval; $\mathrm{HIV}-1$, human immunodeficiency virus type 1; INSTI, integrase strand inhibitor; ISR, injection-site reaction; NNRTI, non-nucleoside reverse transcriptase inhibitor; PI, protease inhibitor; Q8W, every 8 weeks; RNA, ribonucleic acid; RPV, rilpivirine; SoC, standard of care

\section{Supplementary Files}

This is a list of supplementary files associated with this preprint. Click to download.

- SupplementarymaterialsForsubmission.docx 